\title{
ВЛИЯНИЕ МЕЛАТОНИНА НА ИЗМЕНЕНИЯ ЛИПИДНОГО ОБМЕНА ПРИ ИММОБИЛИЗАЦИОННОМ СТРЕССЕ
}

\author{
(С) Сериков В.С., Ляшев Ю.Д.
}

\author{
Кафедра патофизиологии Курского государственного медицинского университета, Курск \\ E-mail: $\underline{\text { medps@yandex.ru }}$
}

\begin{abstract}
В опытах на крысах установлено, что при иммобилизационном стрессе отмечается повышенное содержание неэстерифицированных жирных кислот (НЭЖК), общего холестерина $(\mathrm{OX})$, триглицеридов (ТГ), липопротеидов низкой (ЛПНП) и высокой (ЛПВП) плотности в плазме крови. Введение мелатонина как в дозе 0,2 мг/кг, так и 1,0 мг/кг не оказывало существенного влияния на показатели липидного обмена. Применение гормона в обеих дозах приводило к повышению содержания ЛПВП через 39 часов после иммобилизации по сравнению с контрольной группой. На 4-е сутки отмечается снижение содержания НЭЖК в плазме крови по сравнению с контрольными животными у крыс, получавших мелатонин в дозе 1,0 мг/кг. При введении гормона в дозе 0,2 мг/кг наблюдается более низкая концентрация ЛПВП. На 7-е сутки после иммобилизации наблюдается увеличение концентрации ЛПВП у животных, получавших мелатонин в дозе 1,0 мг/кг.
\end{abstract}

Ключевые слова: стресс, липидный обмен, мелатонин, липопротеиды, холестерин.

\section{INFLUENCE OF MELATONIN ON THE CHANGES IN LIPID METABOLISM \\ IN IMMOBILIZATION STRESS \\ Serikov V.S., Lyashev Yu.D.}

Department of Pathophysiology of Kursk State Medical University, Kursk

The experiments on rats revealed the increase in non-esterified fatty acids (NEFA), cholesterol, triglycerides, and low- and high-density lipoproteins in blood plasma after immobilization stress. The injections of melatonin in the doses 0.2 and 1.0 $\mathrm{mg} / \mathrm{kg}$ had no significant influence on lipid metabolism indices. The administration of hormone in both doses caused the increase in high-density lipoproteins (HDL) content 39 hours after immobilization as compared with thecontrol group. On the fourth day the decrease in NEFA concentration was observed in blood plasma of rats which had been injected with melatonin in the dose $1.0 \mathrm{mg} / \mathrm{kg}$ as compared with the control group. Lower LDL concentration as compared to the control group was revealed after melatonin administration in the dose $0.2 \mathrm{mg} / \mathrm{kg}$. The increase in LDL concentration in rats having received melatonin in the dose $1.0 \mathrm{mg} / \mathrm{kg}$ was observed on the seventh day after immobilization.

Keywords: stress, lipid metabolism, melatonin, lipoproteins, cholesterol.

Ранее установлено, что развитие стрессорной реакции сопровождается изменением всех видов обмена в организме. Нарушения липидного обмена проявляются мобилизацией триглицеридов из жировых депо, что сопровождается повышением концентрации неэстерифицированных жирных кислот (НЭЖК) и холестерина $(\mathrm{OX})$ [5]. Известно, что холестерин и липопротеиды низкой плотности обладают атерогенным действием, поэтому предупреждение увеличения их концентрации в плазме является важной медицинской проблемой.

В настоящее время общепризнано, что мелатонин является одним из ведущих компонентов антистрессорной системы организма [2]. Показано наличие у этого гормона выраженного антиоксидантного эффекта [15]. Ранее нами установлено, что многократное применение мелатонина при хроническом стрессе предупреждает развитие нарушений липидного обмена [11]. Однако особенности влияния мелатонина на изменения липидного обмена при остром стрессе остаются невыясненными.
Целью работы явился анализ влияния мелатонина на стресс-индуцированные изменения липидного обмена в различные периоды после стрессорного воздействия.

\section{МАТЕРИАЛЬ И МЕТОДЫ ИССЛЕДОВАНИЯ}

Работа выполнена на 80 крысах-самцах Вистар. Животные были разделены на 10 групп по 8 крыс в каждой. 8 животных оставались интактными. Остальным моделировали 6-часовой иммобилизационный стресс путем фиксации животного на спине на специальном столике. Животных выводили из эксперимента спустя 39 часов, 4 и 7 суток после окончания иммобилизации. Выбор указанных сроков обусловлен данными литературы о том, что максимальные повреждения внутренних органов развиваются в конце стадии тревоги (39 часов после стресса), а в начале стадии резистентности (на 4 сутки) и через 7 суток после окончания иммобилизации наглядно проявляются 
компенсаторные процессы в поврежденных органах [3].

Исследования проводили с соблюдением принципов, изложенных в Конвенции по защите позвоночных животных, используемых для экспериментальных и других целей (г. Страсбург, Франция, 1986).

Содержание в плазме крови неэстерифицированных жирных кислот (НЭЖК), триглицеридов (ТГ), общего холестерина (OX), липопротеидов очень низкой плотности (ЛПОНП), липопротеидов низкой плотности (ЛПНП) и липопротеидов высокой плотности (ЛПВП) оценивали колориметрическими методами [6, 7]. О концентрации исследуемых соединений судили по изменению оптической плотности образца при использовании волны соответствующей длины.

В работе использован мелатонин (SigmaAldrich, США). Препарат вводили внутрибрюшинно в дозах 0,2 мг/кг или 1,0 мг/кг в $1 \%$ растворе этанола ежедневно 1 раз в сутки в вечернее время в течение 5 дней эксперимента в объеме 0,2 мл. Животные, которых выводили из эксперимента через 39 часов после воздействия, получали 2 инъекции исследуемого гормона, а крысы, которых выводили из эксперимента на 4 сутки, - 4 инъекции. Доза 1,0 мг/кг выбрана на основании данных литературы о высокой активности мелатонина в этой дозе [8]. Эффекты препарата в дозе 0,2 мг/кг исследованы для оценки влияния низких доз мелатонина на изменения липидного обмена при стрессе. Контрольным животным аналогично вводили $1 \%$ раствор этанола.

Статистическую значимость различий средних величин вычисляли по $\mathrm{t}$-критерию Стьюдента после проверки нормальности распределения изучаемых параметров.

\section{РЕЗУЛЬТАТЫ ИССЛЕДОВАНИЯ И ИХ ОБСУЖДЕНИЕ}

Моделирование острого стресса приводит к повышению содержания в плазме крови: общего холестерина на $54,4 \%(\mathrm{p}<0,001)$, триглицеридов на $38,0 \% \quad(\mathrm{p}<0,01), \quad$ ЛПОНП - на $36,0 \%$ $(\mathrm{p}<0,001)$, ЛПНП - на 61,9\% (p<0,001), НЭЖК на $136,7 \% \quad(p<0,001)$, через 39 часов после иммобилизации (табл. 1). Концентрация ЛПВП в плазме крови существенно не изменялась.

Через 4 суток после моделирования стресса содержание НЭЖК остается достоверно более высоким по сравнению с аналогичным показателем у интактных крыс (на 49,4\%, $\mathrm{p}<0,05)$. В этот период наблюдается увеличение концентрации ЛПВП в плазме крови на 12,5\% по сравнению с интактными животными $(\mathrm{p}<0,05)$. При этом остальные изучаемые показатели существенно не отличаются.

Введение мелатонина как в дозе 0,2 мг/кг, так и 1 мг/кг не оказывало существенного влияния на показатели липидного обмена. Применение гормона в обеих дозах приводило к повышению содержания ЛПВП через 39 часов после иммобилизации по сравнению с контрольной группой (на 16,8\% (p<0,05) и на 27,7\% (p<0,01) соответственно). На 4-е сутки отмечается снижение содержания НЭЖК в плазме крови по сравнению с контрольными животными у крыс, получавших мелатонин в дозе 1 мг/кг (на 35,6\%, р <0,01). При введении гормона в дозе 0,2 мг/кг наблюдается более низкая концентрация ЛПВП (на 23,7\%, $\mathrm{p}<0,05)$, однако данный показатель не отличался достоверно от аналогичного у интактных крыс $(\mathrm{p}>0,05)$. Напротив, содержание ЛПНП в этот период у животных, которым вводили исследуемый гормон в дозе 1 мг/кг, было существенно выше по сравнению с контрольной группой (на 36,8\%, $\mathrm{p}<0,05)$, но отсутствуют отличия от аналогичного показателя у интактных крыс.

На 7-е сутки наблюдается увеличение концентрации ЛПВП у животных, получавших мелатонин в дозе 1 мг/кг, (на 32,5\%, p<0,001). Значения остальных изучаемых показателей не отличались достоверно от аналогичных у контрольных животных.

Полученные результаты подтверждают данные литературы о повышении концентрации НЭЖК и ТГ при стрессе [5, 10]. Указанный эффект связывают со стимулирующим влиянием катехоламинов на адипоциты на фоне снижения секреции инсулина, что сопровождается мобилизацией ТГ и эстерификацией НЭЖК вследствие активации аденилатциклазы [5]. Подобные изменения, по мнению ряда авторов [12], являются отражением перестройки метаболизма с углеводного на липидный путь. Повышение содержания OX объясняется торможением его распада в печени из-за накопления перекисей липидов, которые ингибируют ключевой фермент катаболизма холестерина - 7-альфа-гидроксилазы [14]. Стресс вызывает резкое повышение концентрации НЭЖК в плазме, что является одним из сильнейших стимулов образования ЛПОНП и ЛПНП [5].

Только спустя 4 суток после воздействия в начале стадии резистентности отмечается восстановление функциональной активности клеток печени и усиление образования ЛПВП. Пусковым фактором гиперпродукции ЛПВП может быть активация ПОЛ, поскольку известно, что ЛПВП обладают выраженным антиоксидантным действием [4]. 
Влияние мелатонина на показатели липидного обмена в плазме крови крыс в разные сроки после иммобилизации

\begin{tabular}{|c|c|c|c|c|c|c|c|}
\hline Показатель & $\begin{array}{l}\text { Срок после } \\
\text { иммобили- } \\
\text { зации }\end{array}$ & $\begin{array}{c}\text { Содержание } \\
\text { общего } \\
\text { холестерина, } \\
\text { ммоль/л } \\
(\mathrm{M} \pm \mathrm{m})\end{array}$ & $\begin{array}{c}\text { Содержание } \\
\text { триглицеридов, } \\
\text { ммоль/л } \\
(\mathrm{M} \pm \mathrm{m})\end{array}$ & \begin{tabular}{|l} 
Содержание \\
ЛПОНП, \\
ммоль/л \\
$(\mathrm{M} \pm \mathrm{m})$
\end{tabular} & \begin{tabular}{|c|} 
Содержание \\
ЛПНП, \\
ммоль/л \\
$(\mathrm{M} \pm \mathrm{m})$
\end{tabular} & $\begin{array}{c}\text { Содержание } \\
\text { ЛПВП, } \\
\text { ммоль/л } \\
(\mathrm{M} \pm \mathrm{m})\end{array}$ & $\begin{array}{c}\text { Содержание } \\
\text { НЭЖК } \\
\text { ммоль/л } \\
(\mathrm{M} \pm \mathrm{m})\end{array}$ \\
\hline Интактные & & $2,04 \pm 0,02$ & $1,79 \pm 0,12$ & $0,25 \pm 0,02$ & $0,21 \pm 0,02$ & $1,20 \pm 0,05$ & $0,79 \pm 0,07$ \\
\hline \multirow{3}{*}{ Контрольная группа } & 39 часов & $3,15 \pm 0,16^{\mathrm{xxx}}$ & $2,47 \pm 0,10^{\mathrm{xx}}$ & $0,34 \pm 0,03^{\mathrm{xxx}}$ & $0,34 \pm 0,03^{\mathrm{xxx}}$ & $1,19 \pm 0,03$ & $1,87 \pm 0,09^{\mathrm{xxx}}$ \\
\hline & 4 суток & $2,19 \pm 0,05$ & $2,01 \pm 0,11$ & $0,20 \pm 0,02$ & $0,19 \pm 0,02$ & $1,35 \pm 0,05$ & $1,18 \pm 0,09^{\mathrm{x}}$ \\
\hline & 7 суток & $1,88 \pm 0,09$ & $1,73 \pm 0,13$ & $0,17 \pm 0,01^{\mathrm{xx}}$ & $0,16 \pm 0,01$ & $1,17 \pm 0,05$ & $0,79 \pm 0,09$ \\
\hline \multirow{3}{*}{$\begin{array}{c}\text { Группа, получавшая } \\
\text { мелатонин в дозе } \\
0,2 \text { мг/кг }\end{array}$} & 39 часов & $2,91 \pm 0,19$ & $2,31 \pm 0,17$ & $0,35 \pm 0,04$ & $0,34 \pm 0,04$ & $1,39 \pm 0,06^{*}$ & $1,91 \pm 0,10$ \\
\hline & 4 суток & $2,16 \pm 0,11$ & $1,61 \pm 0,17$ & $0,21 \pm 0,02$ & $0,22 \pm 0,03$ & $1,03 \pm 0,08^{*}$ & $0,92 \pm 0,09$ \\
\hline & 7 суток & $1,90 \pm 0,15$ & $1,91 \pm 0,15$ & $0,20 \pm 0,02$ & $0,19 \pm 0,02$ & $1,17 \pm 0,06$ & $0,69 \pm 0,11$ \\
\hline \multirow{3}{*}{$\begin{array}{c}\text { Группа, получавшая } \\
\text { мелатонин в дозе } \\
1,0 \text { мг/кг }\end{array}$} & 39 часов & & & $0,34 \pm 0,03$ & & $1,52 \pm 0,08^{* *}$ & $1,79 \pm 0,09$ \\
\hline & 4 суток & & & $0,26 \pm 0,02$ & $0,26 \pm 0,02 *$ & $1,27 \pm 0,06$ & $0,76 \pm 0,06^{* *}$ \\
\hline & 7 суток & $2,06 \pm 0,11$ & $1,76 \pm 0,09$ & $0,20 \pm 0,02$ & $0,21 \pm 0,02$ & $1,55 \pm 0,04 * * *$ & $0,74 \pm 0,07$ \\
\hline
\end{tabular}

Примечание: * ${ }^{*}$ p $<0,05$ по сравнению с контрольной группой; ${ }^{x}-\mathrm{p}<0,05$ по сравнению с интактной группой; ** - p $<0,01$ по сравнению с контрольной группой; ${ }^{\mathrm{xx}}-\mathrm{p}<0,01$ по сравнению с интактной группой; $* * *-p<0,001$ по сравнению с контрольной группой; ${ }^{\mathrm{xx}}-\mathrm{p}<0,001$ по сравнению с интактной группой.

При стрессе мелатонин проявляет присущие ему стресс-лимитирующие и антиоксидантные свойства $[1,2,9,13,15,16]$. Показано, что он способен предупреждать избыточную секрецию кортикотропин-рилизинг гормона при действии чрезвычайных факторов [17], а также нарушения микроциркуляции [1]. По данным литературы, указанные эффекты наблюдаются при применении мелатонина в дозах от 0,5 до 10 мг/кг. Как показано в нашей работе, гормон способен подавлять стресс-индуцированный липолиз при его многократном введении в дозе 0,2 мг/кг. Тем не менее эффекты мелатонина в дозе 1 мг/кг более выражены.

Таким образом, в работе установлено, что применение мелатонина уменьшает выраженность стресс-индуцированных нарушений липидного обмена у животных, перенесших острый иммобилизационный стресс.

На основании проведенных исследований можно сделать следующие выводы:

1. Установлена динамика изменений показателей липидного обмена в различные периоды после острого иммобилизационного стресса.

2. Применение мелатонина в дозе 1,0 мг/кг приводило к существенному снижению ОХ, ТГ и НЭЖК по сравнению с контрольной группой. При использовании мелатонина в дозе 0,2 мг/кг эффект препарата был несколько ниже, что проявлялось снижением показателей $\mathrm{OX}$ и НЭЖК.

3. Использование мелатонина вызывало повышение ЛПВП в плазме крови крыс после иммобилизационного стресса по сравнению с контрольной группой.

\section{ЛИТЕРАТУРА}

1. Анисимов В.Н., Кветной И.М., Комаров Ф.И., Малиновская Н.К., Рапопорт С.И. Мелатонин в физиологии и патологии желудочно-кишечного тракта. - М. : Советский спорт, 2000. - 84 с.

2. Арушанян Э.Б. Антистрессорные возможности эпифизарного мелатонина // Мелатонин в норме и патологии / Под ред. Комарова Ф.И. - М. : Медицина, 2004. - С. 198-222.

3. Выборова И.С., Ханджав Удвал, Васильева Л.С., Макарова Н.Г. Структура печени в динамике иммобилизационного стресса // Сибир. медиц. журнал. - 2005. - № 3. - С. 30-33.

4. Климов А.Н., Гуревич В.С., Никифорова А.А. Антиоксидантная активность липопротеидов высокой плотности // Бюл. экспер. биол. и мед. 1992. - Т. 108, № 7. - С. 40-42.

5. Климов А.Н., Никульчева Н.Г. Липиды, липопротеиды и атеросклероз. - СПб. : Питер, 1995. - 297 c.

6. Лабораторные методы исследования в клинике / Под ред. В.В. Меньшиковой. - М. : Медицина, 1987. $-368 \mathrm{c}$.

7. Методы исследования в профпатологии / Под ред. О.Г. Архиповой. - М.: Медицина, 1988. - 169 с.

8. Перияов С.С. Мелатонин в системных механизмах эмоционального стресса. - М. : Изд-во РАМН, 2011. - $232 \mathrm{c}$.

9. Сериков В.С., Солин А.В., Лямев Ю.Д., Королев B.A. Влияние мелатонина на содержание продуктов перекисного окисления липидов и активность ферментов антиоксидантной системы в печени крыс, подвергшихся иммобилизационному стрессу // Рос. физиол. журн. им. И.М. Сеченова. 2014. - T. 100, № 4. - С. 458-464.

10. Солин А.В., Корозин В.И., Ляшев Ю.Д. Влияние регуляторных пептидов на стресс-индуцированные 
изменения липидного обмена у экспериментальных животных // Бюл. эксперимен. биол. мед. 2013. - T. 155, № 3. - С. 299-302.

11. Солин А.В., Сериков В.С., Лямев Ю.Д. Влияние опиоидных пептидов и мелатонина на липидный обмен при хроническом стрессе // Курск. науч.практ. вестн. «Человек и его здоровье». - 2013. № 4. - С. 42-45.

12. Трилис Я.Г., Давыдов В.В., Николаев В.И. Взаимодействие основных эндокринных комплексов и процессов метаболизма в динамике стресса // Вест. Санкт-Петербург. гос. мед. акад. им. И.И. Мечникова. - 2006. - № 2. - С. 84-89.

13. Gitto E., Tan D.X., Reiter R.J., Karbownik M., Manchester L.C., Cuzzocrea S., Fulia F., Barberi I. Individual and synergistic antioxidative actions of melatonin: studies with vitamin $\mathrm{E}$, vitamin $\mathrm{C}$, gluthatione, and desferroxamine (desferoxamine) in rat liver homogenates // J. Pharm. Pharmacol. 2001. - Vol. 53, N 9. - P. 1393-1401.

14. HulbertA.I., Turner N., Storlien L.H., Else P. Dietary fats and membrane function: implications for metabolism and disease // Biol.Rev. Camb. Philos. Soc. - 2005. - Vol. 80, N 1. - P. 155-169.

15. Reiter R.J., Tan D.X., Osuna C., Gitto E. Actions of melatonin in the reduction of oxidative stress: a review // J. Biomed. Sci. - 2000. - Vol.7, N 5. P. 444-458.

16. Rodriguez C., Mayo J.C., Sainz R.M., Antolin I., Herrera F., Martin V., Reiter R.J. Regulation of antioxidant enzymes: a significant role for melatonin // Jour. Pineal Res. - 2004. - Vol. 36, N 1. - P. 1-9.

17. Song G.H., Gwee K.A., Moochhala S.M., Ho K.Y. Melatonin attenuates stress-induced defecation: lesson from a rat model of stress-induced gut dysfunction // Neurogastroenterol. Motil. - 2005. - Vol. 17, N 5. P. 744-750. 